tracks would be welcome additions and if the book is addressed to a world-wide medical audience it must also include chest diseases peculiar to tropical countries. How does Perry and Holmes Sellors' book measure up to these demands? The chapters on Anatomy, Physiology and Radiology are good Asthma and the commoner acute inflammatory diseases of the trachea, bronchi, lungs and pleura are adequately covered. There is no separate mention of laryngeal affections presumably because the larynx is considered to lie outside 'the chest'. A long chapter on fungous diseases is excellent. Pulmonary tuberculosis is dealt with very fully in all its aspects. Pulmonary sarcoidosis is covered in five pages, slightly flawed by the erroneous statement that in the Kveim test, the antigen is injected subcutaneously. Intradermal injection is much more likely to yield satisfactory results. Ten essays on lesions of the pleura are particularly well done. The chapters on tumours of the lungs and bronchi are very full and well illustrated. Tropical lung diseases are represented by leprosy (tracheal lesions only, are described, whereas in fact laryngeal affection is much commoner and more serious), pulmonary eosinophilia, paragonimiasis, roundworm infestation, amœbiasis, hydatid diseases and schistosomiasis.

Though whooping cough is dealt with adequately, measles is dismissed in a few lines without guidance on the treatment of pulmonary complications.

On the whole, this well-produced book is a valuable acquisition to the general physician and to the chest specialist who will particularly enjoy such uncommon little extras as the essays on "Sputum", "Respiratory difficulty in the newborn", "Irradiation pneumonia", and "Anæsthesia in chest disease".

\section{Diagnosis and Treatment of Blood Diseases}

M. C. G. IsRaELS, M.D., M.SC., F.R.C.P. Pp. 200 with 11 colour plates. London: William Heinemann, 1963, 35s.

The author states in his introduction that his aim in writing this book is to provide the busy practising physician with modern guidance on diagnosis and treatment without involving the reader in search through much, interesting but impractical, detail as may be found in the larger textbooks of hæmatology. He has drawn on his large clinical experience to distil this information neatly into 200 pages of relatively easy reading.

The author constantly demonstrates his appreciation of day to day clinical problems and gives good clear accounts of the various diseases. The sections on bleeding diseases, reticuloses and diseases of the white cells are specially helpful, but the chapters on the anæmias are perhaps a little pedestrian. There is an interesting section on laboratory investigations with their normal and abnormal ranges, but it is doubtful whether many physicians will gain anything from the short, rather sketchy chapter on clinical examination. The last chapter deals with laboratory techniques but in a book of this sort it is uncertain whether anything is gained by inclusion of these details which can be of use to only a small minority of readers. On the other hand the inclusion, after the index, of eleven excellent colour plates illustrating bone marrow disorders is of considerable help and interest. References are few but well selected. There are one or two statements which may not be widely acceptable, such as the suggestion that iron deficiency is common in hæmolytic anæmia and the normal range of serum bilirubin is given as 1 to $3 \mathrm{mgms} / 100 \mathrm{mls}$. The book as a whole, however, serves its purpose well; it provides a compact up-to-date account of diagnostic methods and treatment and can be recommended for the non-specialist.

\section{Advances in Biology of Skin Vol. IV \\ The Sebaceous Glands}

Edited by William Montagna, Richard A. Ellis and Alene F. Silver. Pp. 260. Oxford, London, New York \& Paris: Pergamon Press. 1963. 80s.

The Brown Symposia are now fixed stars. They function as a sort of instalment plan encyclopedia of the skin, ancillary to Rothman's classic, which, alas, has not been kept up to date. Reviewed in this light their main weakness is the uneasy disproportion between the space taken by the various contributors' own work and the space given by them to other, often earlier works. This defect will be highlighted by the staying power of some of the papers. The Symposia are, of course, not intended to be reviews, but they are patently not accounts only of recent work. In the latest volume for example the mean age of the references at the time of printing was 16 years. My other general criticism is the price: $80 \mathrm{~s}$. is too much for 260 pages of text. I am sure most of us would be pleased to dispense with the gold embossing, glossy paper and half the price.

The latest volume in the series is on "The Sebaceous Glands". The form, now set by honourable precedent, consists of a skirmish in the foothills of function and gross and chemical structure, with an occasional glimpse of the pathological ranges in the distance. But, let us say now (I am putting my conclusions here for weary compulsives who read straight from the beginning to end), that this book, and indeed the rest of the series, are essential to the student of the skin, for nowhere else will he find the subject covered so thoroughly. The first six chapters are anatomical and cover development and comparative anatomy with detailed accounts of the human sebaceous gland including ultra-structure. There is an interesting chapter by A. E. W. Miles on sebaceous glands in human mucosa, and then a chapter on ectopic glands in which fact, after a brave attack, succumbs to a mysterious hypothesis. This is followed by a delightful paper by Kligman who makes a glandful of functions disappear before your very eyes. There are four chapters covering aspects of the metabolism of sebaceous glands and the chemistry of sebum. This includes an extremely full account of analytical methods by V. R. Wheatley. Functionists (pure and disturbed) will find the last three chapters (by Lorinez, Ebling, Strauss and Pochi) particularly useful, since they are a comprehensive review of what is reliably known of the effects of hormones on the sebaceous glands.

\section{The London-A Study in the Voluntary Hospital System}

Edited by A. E. Clark-Kennedy. Vol. 2. 18401948. Pp. 310, illustrated. London: Pitman Medical. 1964. 50s.

As in the first volume of his history, Dr. ClarkKennedy has managed to review not just a century's progress in one large hospital in the East End of 